\title{
Use of the Single-Item Self-Esteem Scale in a Juvenile Delinquent Population: A Convergent Validity Study
}

\author{
David Coker ${ }^{1, *}$ \\ ${ }^{1}$ Advanced Education Program, Fort Hays State University, Hays, Kansas, USA \\ *Corresponding author: Advanced Education Program, Fort Hays State University, Hays, \\ Kansas, USA. E-mail: dccoker@fhsu.edu
}

Received: January 1, 2021 Accepted: March 8, 2021 Published: March 20, 2021

doi:10.5296/ije.v13i1.18145 URL: https://doi.org/10.5296/ije.v13i1.18145

\begin{abstract}
The validity of the Single-Item Self-Esteem Scale (SISE) in adolescents was not well established, and how self-esteem manifested in newly incarcerated juvenile delinquents was poorly described. Using a retrospective study with archival records, the SISE was compared to other measures of self-esteem, grit, mental health, and academic self-concept in a small juvenile detention center in the Midwest of the United States. Demographic data were analyzed, and a correlation, intraclass correlation, and kappa statistic were run to test relationships and reliability. The SISE was found to be a reliable and efficient tool to use with adolescents and juvenile delinquents. Policy recommendations applicable to juvenile delinquents and schools in general give direction using the findings.
\end{abstract}

Keywords: juvenile delinquency, self-esteem, validity, reliability, educational policy 


\section{Introduction}

Within education, self-esteem's importance remains an enigma. Self-esteem has a small but important impact on personal success across the lifespan (Orth et al., 2012), and low self-esteem can lead to negative outcomes in adolescents (McClure et al., 2010; Oshri et al., 2017). Yet, trying to artificially raise self-esteem resulted in a paradox in one study by worsening academic achievement instead of improving it (Forsyth et al., 2007), and another meta-analysis suggested self-esteem produced few benefits in education and life (Baumeister $\&$ Vohs, 2018). The effects of self-esteem on juvenile delinquency continued to be mired in debate, with the not mutually exclusive argument low self-esteem mattered but self-esteem generally rises in adolescence (Bachman et al., 2011; Trzesniewski et al., 2006).

Two central aims of the present study add to existing gaps in the literature. First, the Single-Item Self-Esteem Scale (SISE) has been validated and found reliable for adults but of limited usage in children (Robins et al., 2001). The following study examined convergent validity among an adolescent population in a juvenile detention center. Secondly, there was a paucity of research about the self-esteem of first-time detained juvenile delinquents, so analysis of newly detained juveniles could be of significance in understanding educational needs of delinquents. After a brief literature review, an analysis of the data is presented, and a discussion follows.

\section{Literature Review}

Robins et al. (2001) developed the SISE as a means of a singular concept of self-esteem which could be evaluated with one question. Using a comparison to the Rosenberg Self-Esteem Scale (RSE), the authors found acceptable agreement among children $(\mathrm{rs}=.52)$ but much lower agreement than adults. Other countries, such as Germany, Peru, and Brazil, have translated the SISE and found acceptable psychometric properties for use in the general population (Brailovskaia \& Margraf, 2018; Dominguez-Lara, 2020; Pimentel et al., 2018). No identified study examined the usage of the SISE in adolescents or juvenile delinquents in the United States.

A lengthy history showed delinquency or delinquency association can serve to raise self-esteem in juveniles (Jang \& Thornberry, 1998; F. Rosenberg et al., 1978; M. Rosenberg et al., 1989). A competing perspective discounted enhanced self-esteem in juvenile delinquents when controlling for narcissism (Barry et al., 2007; Donnellan et al., 2005). Erol et al. (2011) found emotionally stable and risk averse individuals generally had high self-esteem, and a meta-analysis by Mier and Ladny (2018) suggested high self-esteem had a significant albeit small effect on preventing engagement in delinquency.

Students with high self-esteem probably have better academic outcomes and better behavior than students with low self-esteem, but the reasons were unclear (Alves-Martins et al., 2002; Çakar \& Tagay, 2017; Wells et al., 2020). The effects of high self-esteem on academic achievement and social relationships were not unidirectional, as self-esteem was generally stable, reciprocal with social relationships, and while high academic achievement predicted 
high self-esteem, the reverse was not true (Harris \& Orth, 2019; Orth \& Robins, 2014; Tetzner et al., 2017). Thapa et al. (2020) found increasing self-esteem through interventions might increase delinquency unless pride in criminal behavior was addressed. Whether for juvenile delinquents or the general population, improvement in social, emotional, and academic outcomes were not as simple as raising self-esteem.

\section{Methods}

The following study sought to investigate two phenomena: Does the SISE have convergent validity in adolescents with another valid and reliable self-esteem instrument, the State Self-Esteem Scale (SSES) (Heatherton \& Polivy, 1991)? What was the nature of self-esteem for juveniles first-time detained in a juvenile detention center? The significance would provide evidence of the suitability of the SISE in adolescents and shed light on the self-esteem of juveniles newly incarcerated. The results could be used to strengthen educational programs for juvenile delinquents and all adolescents.

The study was conducted using Jeffrey's Amazing Statistics Program (JASP Team (2020). JASP (Version 0.14)[Computer software]). The software G*Power suggested, for correlation, a sample size of 194 would be needed for $p=.05, \beta=.20$, and $r=.20$ (Faul et al., 2009). First, the sample was described using descriptive and inferential statistics. Next, three stages of analysis were conducted to examine the use of SISE in an adolescent population: correlational analysis with the SSES and other scales, an intraclass correlation analysis, and kappa statistic. Analysis procedures for concurrent validity of the SISE and SSES were similar to other single-item measures (e.g., Konrath et al., 2014; Robins et al., 2001).

\subsection{Data Collection}

An archival review of records from a regional juvenile detention center in the Midwest in the United States was conducted. Anonymity and confidentiality were of primary importance, so all names and identifying information were stripped before removing the data from the facility. Files were initially stored as a Microsoft Excel file, and all information was checked for completeness and accuracy. Any student who lacked either or both the SISE and SSES were removed from the study. The file was then saved as a CSV file and exported to JASP for analysis.

\subsection{Sample}

Students were selected from one regional juvenile detention center which served primarily suburban and rural students from the years 2014-2020. Students were placed in the detention center by order of a local court. Upon entrance, students were interviewed by the detention center staff to ascertain if students had previously been in secure detention. Within five days of entrance, students completed a school case study with social, emotional, and academic measures. The school had three teachers present daily, with an average attendance of 20 students per day. School operated on a block schedule, and technology enabled electives and interventions. 
The sample included 559 juveniles, with an average age of $15.62(S D=1.06$; Range $=14-17)$ and primarily male $(81.4 \% ; N=455)$, with a small female population $(18.6 \% ; N=104)$. Most students were in high school (grade level $M=9.88 ; S D=1.36$; Range $=6^{\text {th }}-12^{\text {th }}$ ), and the rate of special education $(41 \% ; N=228)$ was high compared to nondelinquents. There were White $(52.4 \% ; N=293)$, Black $(44.7 \% ; N=250)$ and Hispanic $(2.9 \% ; N=16)$ students.

Academically, the students were significantly behind similarly situated peers in reading (grade equivalency $M=6.57$ ) and mathematics (grade equivalency $M=6.83$ ) on the Test of Adult Basic Education (TABE) compared to average grade level of 9.8. Students also completed the Grit-Short scale $(M=3.40 ; S D=0.61)$, the Strengths and Difficulties Questionnaire (SDQ) $(M=15.19 ; S D=5.87)$, Marsh's Mathematics Academic Self-Concept (ASC) Scale $(M=14.55 ; S D=4.00)$, and Marsh's Language Arts Academic Self-Concept Scale $(M=15.99 ; S D=5.29)$. All scales had established reliability and validity (Duckworth \& Quinn, 2009; Goodman, 1997; Marsh, 1990). A juvenile delinquent's grit and ASC were similar to nondelinquent peers, but the SDQ revealed there was a high rate of students in the borderline and abnormal range. The prevalence of borderline and abnormal scores on the SDQ suggested the possibility of mental illness.

Self-esteem was measured using the SISE on a scale of 1-7 $(M=4.65 ; S D=1.81)$ and SSES $(M=73.11 ; S D=12.82)$. Blacks $(M=5.06 ; S D=1.84)$ and Whites $(M=4.27 ; S D=1.70)$ differed significantly on the $\operatorname{SISE}[\mathrm{F}(2,556)=14.01, p=<.001]$, as confirmed by Tukey's test. For the SSES, significant differences were found as well using ANOVA with Welch's correction $[\mathrm{F}(2,41.032)=14.898, p=<.001]$ and Tukey's test. Statistically significant differences on the SISE were also found between males $(M=4.73 ; S D=1.73)$ and females $(M=4.31 ; S D=1.88)$ on an ANOVA test $[\mathrm{F}(1,557)=14.48, p=.035]$. Differences on the SISE by age and grade level were not statistically significant.

The overwhelming majority of students, greater than $95 \%$, had persistent and pervasive problems in regular school before detention. Many students were expelled or attended alternative schools. Attendance and behavioral problems were the norm, and students struggled, as a group, with completing academic activities.

\subsection{Data Analysis}

There were three levels of analysis. First, correlations were run to reveal the strength of relationships between SISE and Grit-S, SDQ, SSES, Mathematics ASC, and English ASC. Then an intraclass correlation coefficient (ICC) and a kappa statistic were conducted. The different statistical analysis explored the relationships toward other constructs and detailed reliability.

Correlation, as shown in Table 1, revealed the SISE had a significant correlation, using Spearman's rho, with SSES, SDQ, and Grit-S. The SDQ's high score means borderline or abnormal, so the direction was negative. Examining the SSES, the correlations with the SDQ and Grit were even stronger, and there was also a correlation with Marsh's mathematics ASC. The SISE did not correlate with the TABE reading or mathematics test. A post priori test was run to see if the SDQ, for students in or above the borderline range, had a statistically 
significant relationship to the SISE. Despite the logistic regression test showing significance, McFadden's pseudo-r revealed only 3\% could be explained. Though Grit and the SDQ were not a focus of the study, the correlations were interesting and deserving of further study.

Table 1. SISE Correlation

\begin{tabular}{|c|c|c|c|c|c|c|c|}
\hline Variable & Statistics & SISE & SSES & SDQ & M ASC & ENG ASC & GRIT \\
\hline \multirow[t]{3}{*}{ 1. SISE } & $\mathrm{n}$ & - & & & & & \\
\hline & Spearman's rho & - & & & & & \\
\hline & p-value & - & & & & & \\
\hline \multirow[t]{3}{*}{ 2. SSES } & $\mathrm{n}$ & 559 & - & & & & \\
\hline & Spearman's rho & $0.465 * * *$ & - & & & & \\
\hline & p-value & $<.001$ & - & & & & \\
\hline \multirow[t]{3}{*}{ 3. SDQ } & $\mathrm{n}$ & 232 & 232 & - & & & \\
\hline & Spearman's rho & $-0.292 * * *$ & $-0.547 * * *$ & - & & & \\
\hline & p-value & $<.001$ & $<.001$ & - & & & \\
\hline \multirow[t]{3}{*}{ 4. M ASC } & $\mathrm{n}$ & 147 & 147 & 145 & - & & \\
\hline & Spearman's rho & 0.121 & $0.279 * * *$ & $-0.243 * *$ & - & & \\
\hline & $\mathrm{p}$-value & 0.144 & $<.001$ & 0.003 & - & & \\
\hline \multirow[t]{3}{*}{ 5. ENG ASC } & $\mathrm{n}$ & 147 & 147 & 145 & 147 & - & \\
\hline & Spearman's rho & 0.056 & 0.124 & $-0.227 * *$ & -0.111 & - & \\
\hline & p-value & 0.504 & 0.133 & 0.006 & 0.180 & - & \\
\hline \multirow[t]{3}{*}{ 6. GRIT } & $\mathrm{n}$ & 148 & 148 & 145 & 146 & 146 & - \\
\hline & Spearman's rho & $0.181 *$ & $0.275 * * *$ & $-0.342 * * *$ & $0.263 * *$ & $0.292 * * *$ & - \\
\hline & $\mathrm{p}$-value & 0.027 & $<.001$ & $<.001$ & 0.001 & $<.001$ & - \\
\hline
\end{tabular}

Note. SISE = Single-Item Self-Esteem Scale. SSES = State Self-Esteem Scale. SDQ = Strengths \& Difficulties Questionnaire. M ASC = Mathematics Academic Self-Concept. ENG ASC $=$ English Academic Self-Concept. GRIT = Grit-Short Scale.

Reliability of the SISE by comparing to the SSES was examined using the ICC and kappa statistic. Using the ICC, a fair agreement was found at .421 $[\mathrm{F}(1,558)=2.45, p=<.001]$. The kappa statistic, identical to Pearson's chi-square test when 2x2 (Feingold, 1992), was examined with the SISE average of 5 and the SSES average of 73 being the cutoff for high. The results were a kappa statistic of $0.347(p=<.001$, agreement of $67.4 \%$; both high $=203$, both low $=174$, SSES high $=90$, and SISE low $=92 ; S E=0.04 ;$ CI 95\% $=.269-.425)$. Even rounding the SISE to 4 as the high cutoff to be conservative still produced a fair agreement. According to Cicchetti (1994) and Sim and Wright (2005), the ICC and kappa statistic have a 
fair to moderate agreement between the SISE and the SSES.

\subsection{Results}

The reliability of the SISE was adequate for use in adolescents to quickly and efficiently measure self-esteem. Similar to findings in the original study (Robins et al., 2001), the SISE had a weaker correlation than found in adults. This study used a different scale, the SSES instead of the RSE, and lends further support the SISE could prove useful in clinical and research settings with adolescents and juvenile delinquents. Reading ability was not correlated, though one could theorize the SSES and RSE, being longer, were more difficult to read and interpret. A possible cause for the weaker association was the different constructs of self-esteem measured by the different instruments, but comparison of findings to past research suggested the SISE performed as expected.

The finding suggested Blacks scored higher than Whites and females scored lower than males. Past findings support these results, lending credence to the validity and reliability because the SISE possessed similar demographic outcomes as other well-known measures of self-esteem (Birndorf et al., 2005). Adolescents generally were found with rising self-esteem, and healthy self-esteem depended on one's coping ability and outlook on the future (Greve et al., 2001; Jackman \& MacPhee, 2017). Meta-analysis of studies found females have generally lower self-esteem (Helwig \& Ruprecht, 2017), and other large-scale studies also were similar in finding the positive discrepancy of self-esteem for Blacks compared to Whites (Adams, 2010; Kiecolt \& Hughes, 2017). There were not significant differences by age or grade.

Juvenile delinquents did not score noticeably different than nondelinquents on a measure of self-esteem, consistent with findings placing juvenile delinquents similar to normal adolescent development (Orth et al., 2018). Of note, there was a relationship of the SISE with the SDQ and the Grit-S scale. The SDQ's significance suggested the presence of mental illness lowered ASC, grit, and self-esteem. The direction or meaning of the relationship were not explained with the tests utilized. Three major findings emerged: the use of the SISE, the self-esteem of juvenile delinquents, and policy recommendations.

\section{Discussion}

The correlation, ICC, and kappa statistic suggested the SISE was an efficient, low intrusive means to measure self-esteem in adolescents and juvenile delinquents. Compared to other measures of self-esteem (Bachman et al., 2011; Bleidorn et al., 2016), the SISE was comparable and found adolescents had high self-esteem, Blacks had higher self-esteem than Whites, and males were higher than females. Though the study was in a juvenile detention center, juvenile delinquents appeared more like nondelinquents than different.

The nature and significance of self-esteem in juvenile delinquents remain problematic and debatable, but low self-esteem did not define the sample. Few studies, such as the present one, examined newly detained juvenile delinquents. Researchers have long found self-esteem and delinquency have a weak relationship, and delinquency can serve to raise self-esteem, as 
stated by Kaplan's theory (Bynner et al., 1981; Jang \& Thornberry, 1998; F. Rosenberg et al., 1978). Self-esteem was one of many characteristics which affect the actions of juvenile delinquents and all adolescents, and researchers were apt to consider other factors, such as risk-taking styles, callous unemotional characteristics, and mental health (Barendregt et al., 2015; Jackman \& MacPhee, 2017; Walker et al., 2020). Possibly Kaplan's theory explained how juveniles newly incarcerated, which would be hypothesized to be a calamitous low point in one's life, nevertheless, did not demonstrate a low self-esteem in the juvenile delinquent population.

If self-esteem cannot be easily generalized as one direction or the other, then there should be pause for the many nostrums circulating in education today. Current educational initiatives in many locations follow the fashionable social and emotional learning (SEL) theory, which believes if educators would teach a psychoeducational curriculum around simplistic topics, meaningful changes and improvements in school would occur instanter. The simpler seems to be the better, around ideas such as grit ("Try hard and don't give up"), a growth mindset ("I think I can, I think I can"), and self-esteem ("I love myself"), students and schools can transform similar to the Sneetches going in and out of the star-off and star-on machine in Dr. Seuss's The Sneetches. The teachers were like the fix-it-up chappie, introducing different nostrums year after year without the promised results, and SEL displaced the traditional curricula required for success in college and career programs.

Concerning juvenile delinquents, there were observed problems (e.g., the SDQ), but self-esteem might not be the panacea claimed. Many programs call for extreme praise, such as at the rate of praise to reprimand as high 9:1 (Caldarella et al., 2019), yet many studies suggested praise was either not effective or might be harmful (Brummelman et al., 2017; Lepper et al., 1973; Gneezy et al., 2019; Moore et al., 2019). Other efforts included eliminating grade retention because it was harmful to students (Hughes et al., 2018; Klapproth et al., 2016) and the negative effects of school exclusionary policies in favor of letting students escape meaningful discipline (Anyon et al., 2014; Eyllon et al., 2020)

Yet, mantras around grit, self-esteem, growth mindset, and other constructs did not transform students and instill academic and social skills with emotional stability. Extreme praise with extreme misbehavior, passing despite pervasive and obvious lack of effort or achievement, and making bad behavior good often led to unintended consequences (the no retention, no exclusion policy, in tandem with an avalanche of praise and rewards, lacked mechanisms to make students work and behave). The confusion of rampant defiance and disruption with hearing $90 \%$ of the time praise should be replaced with the realization not only does praise lack a strong evidence background to change behavior, but why would one change if all one hears and sees were compliments.

Many practitioners and programs operated off the premise juvenile delinquents needed improved self-esteem to avoid future criminal behavior. Yet a paradox existed, as delinquency might be a protective effect against low self-esteem (Gold, 1978). Delinquent behavior and nonconformity, specifically violence, probably increased self-esteem, and association with fellow delinquents enhanced self-esteem (Jang \& Thornberry, 1998; Muslu 
et al., 2017; Woessner \& Schneider, 2013). Assumptions about self-esteem and the complex interaction with other behaviors should not be made without considering contextual factors.

Teachers should not play psychotherapist, but building positive relationships in a safe environment is paramount with the acceptance some children's behavior would be incongruent with such an ecology. Gearheart and Tucker (2020) have a replacement for the one-size-fits-all approach: Individualization of responses and case management hold the most promise. No training, education, or professional development program for adults with severe problems will give overwhelming praise, promise promotion disassociated from effort or attendance, continue to allow disruptive and defiant behavior as a preferable environment for peers, and offer only mantras to increase positivity as the main response. There exists a paradox: Grit and growth mindset emphasize effort and a positive future orientation and call into question giving praise such as one is smart, yet self-esteem programs and praise regiments offer the opposite. One cannot simply raise one characteristic in isolation and fix all which ails, and teachers cannot easily sort out psychoeducational constructs, such as self-esteem, to result in a meaningful intervention for students.

\section{Conclusion}

The SISE was found to be a valid and reliable instrument for juvenile delinquents and adolescents in general. Boden et al. (2008) pointed out the problem of self-esteem: Other psychological characteristics explain much of the variance of self-esteem and later problems. Focusing on improving self-esteem without concomitant achievement has not been effective and possibly could be better funneled into making adolescents resilient (Baumeister et al., 2003; Martínez-Martí \& Ruch, 2017). In juvenile detention centers, students brought psychological and substance abuse issues which placed the youth in a peer group similarly situated. The value of self-esteem in later life remains problematic and multifaceted, so educators should exercise caution in bandwagon approaches which promise large benefits. Adolescents and juvenile delinquents, on average, have a raising self-esteem as one progresses through middle and high school. Students who have problems need identified, but mental healthcare workers are better positioned to make sense of findings than teachers.

Low self-esteem in adolescents related to mental health problems across the lifespan, but other psychological factors moderated and mediated the effects (Boden et al., 2008; Harpin et al., 2016; Jennings et al., 2018). A discrepancy in self-verification or reflected appraisal, both within the individual and group context, negatively impacted emotions and self-regulation (Cast \& Burke, 2002; Keith \& Scheuerman, 2018). Self-esteem depends on many factors, and different types of relationships can produce different responses in adolescents (Fu et al., 2017). Research produced mixed, often contradictory results, with the need to consider juvenile delinquents on a case-by-case basis when examining self-esteem and possible interventions. 


\section{Limitations}

Despite an adequate sample size, there were limitations. First, only one location was included in the sample, which might hamper generalizability. Secondly, repeated administration would improve reliability studies. Third, having access to the scores on the individual questions of the SSES, Grit-S, and the two ASC scales would allow for more in-depth analysis. Finally, there was the possibility nondelinquents might differ from juvenile delinquents.

Future research should consider other variables, such as the SDQ, ecological factors, time in detention, and age of onset. Building off Krauss et al. (2018), self-esteem does not happen in a vacuum, and a holistic approach to social, mental, academic, and physical factors could further define the dimensions of self-esteem in a juvenile delinquent population. Another concern is the refinement of the type of self-esteem measured by the different instruments.

\section{Conflict of Interest}

There are no conflicts of interest. All data were obtained and handled in an ethical manner.

\section{References}

Adams, P. E. (2010). Understanding the different realities, experience, and use of self-esteem between Black and White adolescent girls. Journal of Black Psychology, 36(3), 255-276. https://doi.org/10.1177\%2F0095798410361454

Alves-Martins, M., Peixoto, F., Gouveia-Pereira, M., Amaral, V., \& Pedro, I. (2002). Self-esteem and academic achievement among adolescents. Educational Psychology, 22(1), 51-62. https://doi.org/10.1080/01443410120101242

Anyon, Y., Jenson, J. M., Altschul, I., Farrar, J., McQueen, J., Greer, E., ... \& Simmons, J. (2014). The persistent effect of race and the promise of alternatives to suspension in school discipline outcomes. Children and Youth Services Review, 44, 379-386. https://doi.org/10.1016/j.childyouth.2014.06.025

Bachman, J. G., O’Malley, P. M., Freedman-Doan, P., Trzesniewski, K. H., \& Donnellan, M. B. (2011). Adolescent self-esteem: Differences by race/ethnicity, gender, and age. Self and Identity, 10(4), 445-473. https://doi.10.1080/15298861003794538

Barendregt, C. S., Van der Laan, A. M., Bongers, I. L., \& Van Nieuwenhuizen, C. (2015). Adolescents in secure residential care: the role of active and passive coping on general well-being and self-esteem. European Child \& Adolescent Psychiatry, 24(7), 845-854. https://doi.org/10.1007/s00787-014-0629-5

Barry, C. T., Grafeman, S. J., Adler, K. K., \& Pickard, J. D. (2007). The relations among narcissism, self-esteem, and delinquency in a sample of at-risk adolescents. Journal of Adolescence, 30(6), 933-942. https://doi.org/10.1016/j.adolescence.2006.12.003 
Baumeister, R. F., Campbell, J. D., Krieger, J. L., \& Vohs, K. D. (2003). Does high self-esteem cause better performance, interpersonal success, happiness, or healthier lifestyles? American Psychological Society, 4(1), 2-6. https://doi.org/10.1111/1529-1006.01431

Baumeister, R. F., \& Vohs, K. D. (2018). Revisiting our reappraisal of the (surprisingly few) benefits of high self-esteem. Perspectives on Psychological Science, 13(2), 137-140. https://doi.org/10.1177/1745691617701185

Birndorf, S., Ryan, S., Auinger, P., \& Aten, M. (2005). High self-esteem among adolescents: Longitudinal trends, sex differences, and protective factors. Journal of Adolescent Health, 37(3), 194-201. https://doi.org/10.1016/j.jadohealth.2004.08.012

Bleidorn, W., Arslan, R. C., Denissen, J. J., Rentfrow, P. J., Gebauer, J. E., Potter, J., \& Gosling, S. D. (2016). Age and gender differences in self-esteem-a cross-cultural window. Journal of Personality and Social Psychology, 111(3), 396-410.

Boden, J. M., Fergusson, D. M., \& Horwood, L. J. (2008). Does adolescent self-esteem predict later life outcomes? A test of the causal role of self-esteem. Development and Psychopathology, 20(1), 319-339. https://doi.org/10.1017/S0954579408000151

Brailovskaia, J., \& Margraf, J. (2018). How to measure self-esteem with one item? Validation of the German single-item self-esteem scale (G-SISE). Current Psychology, 1-11. https://doi.org/10.1007/s12144-018-9911-X

Brummelman, E., Nelemans, S. A., Thomaes, S., \& Orobio de Castro, B. (2017). When parents' praise inflates, children's self-esteem deflates. Child Development, 88(6), 1799-1809. https://doi.org/10.1111/cdev.12936

Bynner, J. M., O'Malley, P. M., \& Bachman, J. G. (1981). Self-esteem and delinquency revisited. Journal of Youth and Adolescence, 10(6), 407-441. https://doi.org/10.1007/BF02087937

Çakar, F. S., \& Tagay, Ö. (2017). The mediating role of self-esteem: The effects of social support and subjective well-being on adolescents' risky behaviors. Educational Sciences: Theory \& Practice, 17(3). https://doi.org/10.12738/estp.2017.3.0024

Caldarella, P., Larsen, R. A., Williams, L., Wills, H. P., \& Wehby, J. H. (2019). Teacher praise-to-reprimand ratios: Behavioral response of students at risk for EBD compared with typically developing peers. Education and Treatment of Children, 42(4), 447-468. https://doi.org/10.1353/etc.2019.0021

Cast, A. D., \& Burke, P. D. (2002). A theory of self-esteem. Social Forces, 80, 1041-1068. https://doi.org/10.1353/sof.2002.0003

Cicchetti, D. V. (1994). Guidelines, criteria, and rules of thumb for evaluating normed and standardized assessment instruments in psychology. Psychological Assessment, 6(4), 284-290. https://doi.org/10.1037/1040-3590.6.4.284 
Dominguez-Lara, S. (2020). Primeras evidencias de validez y confiabilidad de la Single-Item Self-Esteem Scale (SISE) en universitarios peruanos. Educación Médica, 21(1), 63-64. https://doi.org/10.1016/j.edumed.2018.11.007

Donnellan, M. B., Trzesniewski, K. H., Robins, R. W., Moffitt, T. E., \& Caspi, A. (2005). Low self-esteem is related to aggression, antisocial behavior, and delinquency. Psychological Science, 16(4), 328-335. https://doi.org/10.1111/j.0956-7976.2005.01535.x

Duckworth, A. L., \& Quinn, P. D. (2009). Development and validation of the Short Grit Scale (Grit-S). Journal of Personality Assessment, 91, 166-174. https://doi.org/10.1080/00223890802634290

Erol, R. Y., \& Orth, U. (2011). Self-esteem development from age 14 to 30 years: A longitudinal study. Journal of Personality and Social Psychology, 101(3), 607-619. https://doi.org/10.1037/a0024299

Eyllon, M., Salhi, C., Griffith, J. L., \& Lincoln, A. K. (2020). Exclusionary school discipline policies and mental health in a national sample of adolescents without histories of $\begin{array}{lllll}\text { suspension } & \text { or } & \text { expulsion. } & \text { Youth } & \text { Society. }\end{array}$ https://doi.org/10.1177\%2F0044118X20959591

Faul, F., Erdfelder, E., Buchner, A., \& Lang, A.-G. (2009). Statistical power analyses using G*Power 3.1: Tests for correlation and regression analyses. Behavior Research Methods, 41, 1149-1160. https://doi.org/10.3758/BRM.41.4.1149

Feingold, Marcia (1992). The equivalence of Cohen's kappa and Pearson's chi-square statistics in the $2 \times 2$ table. Educational and Psychological Measurement, 52(1), 57-61. https://doi.org/10.1177\%2F001316449205200105

Forsyth, R. D., Lawrence, N. K., Burnette, J. L., \& Baumeister, R. F. (2007). Attempting to improve the academic performance of struggling college students by bolstering their selfesteem: An intervention that backfired. Journal of Social and Clinical Psychology, 26(4), 447-459. https://doi.org/10.1521/jscp.2007.26.4.447

Fu, X., Padilla-Walker, L. M., \& Brown, M. N. (2017). Longitudinal relations between adolescents' self-esteem and prosocial behavior toward strangers, friends and family. Journal of Adolescence, 57, 90-98. https://doi.org/10.1016/j.adolescence.2017.04.002

Gneezy, U., List, J. A., Livingston, J. A., Qin, X., Sadoff, S., \& Xu, Y. (2019). Measuring success in education: the role of effort on the test itself. American Economic Review: Insights, 1(3), 291-308. https://10.1257/aeri.20180633

Gold, M. (1978). Scholastic experiences, self-esteem, and delinquent behavior: A theory for alternative schools. Crime and Delinquency, 24, 294-295. https://doi.org/10.1177/001112877802400304

Goodman, R. (1997). The Strengths and Difficulties Questionnaire: A research note. Journal of Child Psychology and Psychiatry, 38, 581-586. https://doi.org/10.1111/j.1469-7610.1997.tb01545.x 
Greve, W., EnZmann, D., \& Hosser, D. (2001). The stabilization of self-esteem among incarcerated adolescents: Accommodative and immunizing processes. International Journal of Offender Therapy and Comparative Criminology, 45, 749-768. https://doi.org/10.1177/0306624x01456008

Harpin, V., Mazzone, L., Raynaud, J. P., Kahle, J., \& Hodgkins, P. (2016). Long-term outcomes of ADHD: A systematic review of self-esteem and social function. Journal of Attention Disorders, 20, 295-305. https://doi.org/10.1177/1087054713486516

Harris, M. A., \& Orth, U. (2019). The link between self-esteem and social relationships: A meta-analysis of longitudinal studies. Journal of Personality and Social Psychology, 119(6), 1459-1477. https://doi.org/10.1037/pspp0000265

Heatherton, T. F., \& Polivy, J. (1991). Development and validation of a scale for measuring state self-esteem. Journal of Personality and Social Psychology, 60(6), 895-910. https://psycnet.apa.org/doi/10.1037/0022-3514.60.6.895

Helwig, N. E., \& Ruprecht, M. R. (2017). Age, gender, and self-esteem: A sociocultural look through a nonparametric lens. Archives of Scientific Psychology, 5(1), 19. https://psycnet.apa.org/doi/10.1037/arc0000032

Hughes, J. N., West, S. G., Kim, H., \& Bauer, S. S. (2018). Effect of early grade retention on school completion: A prospective study. Journal of Educational Psychology, 110(7), 974-991. https://psycnet.apa.org/doi/10.1037/edu0000243

Jackman, D. M., \& MacPhee, D. (2017). Self-esteem and future orientation predict adolescents' risk engagement. The Journal of Early Adolescence, 37(3), 339-366. https://doi.org/10.1177\%2F0272431615602756

Jang, S. J., \& Thornberry, T. P. (1998). Self-esteem, delinquent peers, and delinquency: A test of the self-enhancement thesis. American Sociological Review, 63(4), 586-598 https://doi.org/10.2307/2657269

Jennings, W. G., Maldonado-Molina, M., Fenimore, D. M., Piquero, A. R., Bird, H., \& Canino, G. (2018). The linkage between mental health, delinquency, and trajectories of delinquency: Results from the Boricua Youth Study. Journal of Criminal Justice, 62, 66-72. https://doi.org/10.1016/j.jcrimjus.2018.08.003

Keith, S., \& Scheuerman, H. L. (2018). The criminal self-view: How do identity discrepancies affect emotions and projected conformity among offenders? Sociological Inquiry, 88, 576-598. https://doi.org/10.1111/soin.12222

Kiecolt, K. J., \& Hughes, M. (2017). Racial identity and the quality of life among blacks and whites in the US. Social Science Research, 67, 59-71. https://doi.org/10.1016/j.ssresearch.2017.08.008

Klapproth, F., Schaltz, P., Brunner, M., Keller, U., Fischbach, A., Ugen, S., \& Martin, R. (2016). Short-term and medium-term effects of grade retention in secondary school on 
academic achievement and psychosocial outcome variables. Learning and Individual Differences, 50, 182-194. https://doi.org/10.1016/j.lindif.2016.08.014

Konrath, S., Meier, B. P., \& Bushman, B. J. (2014). Development and validation of the single item narcissism scale (SINS). PLOS One, 9(8), e103469. https://doi.org/10.1371/journal.pone.0103469

Krauss, S., Orth, U., \& Robins, R. W. (2020). Family environment and self-esteem development: A longitudinal study from age 10 to 16. Journal of Personality and Social Psychology, 119(2), 457-478. https://doi.org/10.1037/pspp0000263

Lepper, M. R., Greene, D., \& Nisbett, R. E. (1973). Undermining children's intrinsic interest with extrinsic reward: A test of the" overjustification" hypothesis. Journal of Personality and social Psychology, 28(1), 129-137. https://psycnet.apa.org/doi/10.1037/h0035519

Marsh, H. W. (1990). The structure of academic self-concept: The Marsh/Shavelson model. $\begin{array}{lllll}\text { Journal of } & \text { Educational } & \text { Psychology, } & 82(4), & \end{array}$ https://doi.org/10.1037//0022-0663.82.4.623

Martínez-Martí, M. L., \& Ruch, W. (2017). Character strengths predict resilience over and above positive affect, self-efficacy, optimism, social support, self-esteem, and life satisfaction. Journal of Positive Psychology, 12(2), 110-119. https://doi.org/10.1080/17439760.2016.1163403

McClure, A. C., Tanski, S. E., Kingsbury, J., Gerrard, M., \& Sargent, J. D. (2010). Characteristics associated with low self-esteem among US adolescents. Academic Pediatrics, 10(4), 238-244. https://doi.org/10.1016/j.acap.2010.03.007

Mier, C., \& Ladny, R. T. (2018). Does self-esteem negatively impact crime and delinquency? A meta-analytic review of 25 years of evidence. Deviant Behavior, 39(8), 1006-1022. https://doi.org/10.1080/01639625.2017.1395667

Moore, T. C., Maggin, D. M., Thompson, K. M., Gordon, J. R., Daniels, S., \& Lang, L. E. (2019). Evidence review for teacher praise to improve students' classroom behavior. Journal of Positive Behavior Interventions, 21(1), 3-18. https://doi.org/10.1177\%2F1098300718766657

Muslu, G. K., Cenk, S. C., \& Sarlak, D. (2017). An analysis of the relationship between high school students' tendency toward violence, self-esteem, and competitive attitude. Journal of Interpersonal Violence, 63(4), 1-21. https://doi.org/10.2307/2657269

Orth, U., Erol, R. Y., \& Luciano, E. C. (2018). Development of self-esteem from age 4 to 94 years: A meta-analysis of longitudinal studies. Psychological Bulletin, 144(10), 1045-1080. https://doi.org/10.1037/bul0000161

Orth, U., \& Robins, R. W. (2014). The development of self-esteem. Current Directions in Psychological Science, 23(5), 381-387. https://doi.org/10.1177/0963721414547414 
Orth, U., Robins, R. W., \& Widaman, K. F. (2012). Life-span development of self-esteem and its effects on important life outcomes. Journal of Personality and Social Psychology, 102(6), 1271-1288. https://doi.org/10.1037/a0025558

Oshri, A., Carlson, M. W., Kwon, J. A., Zeichner, A., \& Wickrama, K. K. (2017). Developmental growth trajectories of self-esteem in adolescence: associations with child neglect and drug use and abuse in young adulthood. Journal of Youth and Adolescence, 46(1), 151-164. https://doi.org/10.1007/s10964-016-0483-5

Pimentel, C. E., Silva, F. M. de S. M., da Santos, J. L. F. dos, Oliveira, K. G., Freitas, N. B. C., Couto, R. N., \& Brito, T. R. de S. (2018). Single-Item Self-Esteem Scale: Adaptação Brasileira, relações com personalidade e comportamentos pró-sociais. Psico-USF, 23(1), 1-11. https://doi.org/10.1590/1413-82712018230101

Robins, R. W., Hendin, H. M., \& Trzesniewski, K. H. (2001). Measuring global self-esteem: Construct validation of a single-item measure and the Rosenberg Self-Esteem Scale. Personality and Social Psychology Bulletin, 27(2), 151-161. https://doi.org/10.1177\%2F0146167201272002

Rosenberg, F. R., Rosenberg, M., \& McCord, J. (1978). Self-esteem and delinquency. Journal of Youth and Adolescence, 7(3), 279-294. https://doi.org/10.1007/BF01537978

Rosenberg, M., Schooler, C., \& Schoenbach, C. (1989). Self-esteem and adolescent problems: Modeling reciprocal effects. American Sociological Review, 54(6), 1004-1018. https://doi.org/10.2307/2095720

Sim, J., \& Wright, C. C. (2005). The kappa statistic in reliability studies: use, interpretation, and sample size requirements. Physical Therapy, 85(3), 257-268. https://doi.org/10.1093/ptj/85.3.257

Tetzner, J., Becker, M., \& Maaz, K. (2017). Development in multiple areas of life in adolescence: Interrelations between academic achievement, perceived peer acceptance, and self-esteem. International Journal of Behavioral Development, 41(6), 704-713. https://doi.org/10.1177/0165025416664432

Thapa, S., Brown, S. L., \& Skilling, T. A. (2020). The relationship between self-esteem, gender, criminal attitudes, and recidivism in a youth justice sample. Criminal Justice and Behavior, 48(4), 539-555. https://doi.org/10.1177\%2F0093854820977577

Trzesniewski, K. H., Donnellan, M. B., Moffitt, T. E., Robins, R. W., Poulton, R., \& Caspi, A. (2006). Low self-esteem during adolescence predicts poor health, criminal behavior, and limited economic prospects during adulthood. Developmental Psychology, 42(2), 381-390. https://psycnet.apa.org/doi/10.1037/0012-1649.42.2.381

Walker, T. M., Robertson, E. L., Frick, P. J., Ray, J. V., Thornton, L. C., Myers, T. D. W., ... \& Cauffman, E. (2020). Relationships among callous-unemotional traits, future orientation, optimism, and self-esteem in justice-involved adolescents. Journal of Child and Family Studies, 29(9), 2434-2442. https://doi.org/10.1007/s10826-020-01770-w 


\section{Macrothink}

Wells, A. E., Hunnikin, L. M., Ash, D. P., \& Van Goozen, S. H. (2020). Low self-esteem and impairments in emotion recognition predict behavioural problems in children. Journal of Psychopathology and Behavioral Assessment, 42, 693-201. https://doi.org/10.1007/s10862-020-09814-7

Woessner, G., \& Schneider, S. (2013). The role of self-control and self-esteem and the impact of early risk factors among violent offenders. Criminal Behavior and Mental Health, 23(2), 99-112. https://doi.org/10.1002/cbm.1863

\section{Copyright Disclaimer}

Copyright for this article is retained by the author(s), with first publication rights granted to the journal.

This is an open-access article distributed under the terms and conditions of the Creative Commons Attribution license (http://creativecommons.org/licenses/by/3.0/). 